RASĀYAN J. Chem.

Vol. 12 | No. 4 |1872 - 1880| October - December | 2019 ISSN: 0974-1496 | e-ISSN: 0976-0083 | CODEN: RJCABP

RJC http://www.rasayanjournal.com http://www.rasayanjournal.co.in

\title{
AN EXPERIMENTAL STUDY ON SURFACE MODIFIER ASSISTED EXFOLIATION OF MOLYBDENUM DISULPHIDE IN A MIXED SOLVENT
}

\author{
Kalyani Sreekumar,", B. Bindhu ${ }^{1}$, K. Veluaraja ${ }^{2}$ and Reena V. L. ${ }^{3}$ \\ ${ }^{1}$ Department of Physics, Noorul Islam Centre for Higher Education, \\ Kumaracoil, Thuckalay-629180 \\ ${ }^{2}$ School of Advanced Sciences, VIT University, Vellore-632014, Tamil Nadu, India \\ ${ }^{3}$ Siddha Central Research Institute, Central Council for Research in Siddha, \\ Chennai-600106, India \\ *E-mail: kalyani.sreekumar@gmail.com
}

\begin{abstract}
Molybdenum disulphide $\left(\mathrm{MoS}_{2}\right)$ is a layered transitional metal dichalcogenide that exhibits unique properties when isolated into one or few layers. $\mathrm{MoS}_{2}$ finds applications in electronics and optoelectronics, along with the ability to act as host materials to polymers. In this paper, we report the successful exfoliation and modification of $\mathrm{MoS}_{2}$ with Lithium salt of 6 amino hexanoic acids (Li-AHA) in a mixed solvent of N-Methyl-2-Pyrrolidone (NMP) and deionized water. The X-ray diffraction studies showed reduction in size accompanied by increased strain, which indicates exfoliation. Photoluminescence was proved for the exfoliated sample using photoluminescence spectroscopy. The antimicrobial study results showed that the exfoliated $\mathrm{MoS}_{2}$ had better zone of inhibition than pristine $\mathrm{MoS}_{2}$.
\end{abstract}

Keywords: $\mathrm{MoS}_{2}$, Exfoliation, Li-AHA, Photoluminescence, Antimicrobial

(C) RASĀYAN. All rights reserved

\section{INTRODUCTION}

Layered substances are of fascinating interest in the field of research due to their unique crystallographic properties. There have been many reports that these layered materials, upon various treatments, can be isolated into single or few-layered substances. ${ }^{1}$ These single-layered two dimensional (2D) materials show enhanced properties than that of their bulk counterpart. ${ }^{2-5}$ Among these $2 \mathrm{D}$ materials, molybdenum disulphide $\left(\mathrm{MoS}_{2}\right)$ is a prominent one, due to the various properties being exhibited by the material. The crystal structure of $\mathrm{MoS}_{2}$ consists of layers of Mo stacked between two sulfide planes which are stacked and separated by van-der Waals forces. Due to thickness induced quantum confinement, a transition occurs from an indirect to direct bandgap, at the few to monolayer limit. ${ }^{6}$ Single layered $\mathrm{MoS}_{2}$ possess unique physical as well as chemical properties and are potentially utilizable as hydrogen evolution catalysts. ${ }^{7-10}$ Also, there have been many studies reporting the efficiency of $\mathrm{MoS}_{2}$ as components of electronics and optoelectronic devices. ${ }^{11-16}$ It was suggested that single-layered $\mathrm{MoS}_{2}$ can in some ways replace graphene, in applications where it requires thin and transparent semiconductors due to the non zero energy gap present in $\mathrm{MoS}_{2}{ }^{17}$ The size-dependent optical and electronic properties make $\mathrm{MoS}_{2}$, one of the most researched transitional metal dichalcogenides (TMD) ${ }^{50}$.

The various types of techniques for isolating layers of $\mathrm{MoS}_{2}$ include, Scotch tape assisted micromechanical exfoliation ${ }^{18-19}$, intercalation assisted exfoliation ${ }^{20-21}$, solution exfoliation ${ }^{22-23}$, physical vapor deposition $^{24-25}$, hydrothermal synthesis ${ }^{26}$, electrochemical synthesis ${ }^{27}$, sulfurization of molybdenum oxides. ${ }^{28}$ Among these different methods, liquid exfoliation method is a general simple technique with better exfoliation results. ${ }^{49}$ Shen $^{53}$ et al. had reported that mechanical agitation using sonication method is sufficient to isolate monolayers, from their bulk counterpart. This method helps in forming stable dispersions. Dispersions of volumes typically in the range of hundreds of milliliters can be produced Rasayan J. Chem., 12(4), 1872-1880(2019)

http://dx.doi.org/10.31788/RJC.2019.1245332 
using the method of sonication ${ }^{54}$ Nanosheets or $2 \mathrm{D}$ materials produced using this method seems to have less basal plane defects. ${ }^{55}$ O"Neill et.al ${ }^{51}$, had reported successful exfoliation of $\mathrm{MoS}_{2}$ in N-methyl-2pyrrolidone (NMP) in the absence of surfactants through the use of a carefully optimized solvent and prolonged aggressive mechanical agitation. The surface tension of NMP $\left(40 \mathrm{~mJ} / \mathrm{m}^{2}\right)$ is similar to estimated surface energies of few-layered $\mathrm{MoS}_{2}\left(46.5 \mathrm{~mJ} / \mathrm{m}^{2}\right) .{ }^{52}$ A systematic study of the stability of NMP during probe sonication demonstrates that NMP undergoes autoxidation that, in the presence of $\mathrm{O}_{2}$ and $\mathrm{H}_{2} \mathrm{O}$, results in the formation of hydroperoxides. ${ }^{50}$ These active species oxidize $\mathrm{MoS}_{2}$ and facilitate exfoliation. Forsberg et.al ${ }^{56}$ had reported the exfoliation of $\mathrm{MoS}_{2}$ in water without any additives, but the dispersions were not much stable. The weak interlayer interaction and a large separation of $0.615 \mathrm{~nm}$ between $\mathrm{MoS}_{2}$ layers enable the intercalation and easy diffusion of the Li-ions. Bindhu et al. ${ }^{39}$ had reported the successful exfoliation of $\mathrm{MoS}_{2}$ using Li-AHA in deionized water.

The present paperwork lay platform for the effective exfoliation of $\mathrm{MoS}_{2}$ using a mixed solvent of NMP and water in the presence of Li-AHA. The results were compared with the samples exfoliated in solvents without the modifier. The samples were studied using X-ray Diffraction analysis (XRD), Fourier transforms Infrared Spectroscopy (FTIR) and Scanning Electron Microscope (SEM). The samples with better exfoliation were subjected to photoluminescence and antimicrobial properties to find out the biological attributes and applications of the material.

\section{EXPERIMENTAL}

\section{Materials}

The following materials are used in our experimental work:

Molybdenum Disulphide [HPLC, LR; MW: 160.06], 6-Aminohexanoic acid [Sigma Aldrich, Fluka Analytical, NT; MW: 131.17], Lithium Hydroxide (Monohydrate) [Molychem, GR; MW: 41.96] and NMethyl-2-Pyrrolidone [RFCL, MW: 99.13].

\section{Characterization}

The crystal structure of the material was studied by X-Ray Diffraction (Philips X-Pert Pro.). The X-ray of wavelength $(\lambda=1.54 \AA)$ emanating from copper target filtered through nickel was used for our diffraction study. The XRD patterns were recorded with a step scan with step size of 0.05 between $5^{\circ}$ and $80^{\circ}(2 \theta)$. The Fourier Transform Infrared Spectrum was recorded using (Thermo Electron Scientific). Photoluminescence property of the sample was studied using (JASCO Corp., FP-750, Rev. 1.00). The surface morphology of the sample was examined using FESEM, CARL Zeiis Germany, Model Ultra 55 FESEM with $1 \mathrm{~nm}$ resolution, detector is INLENS.

\section{Sample Preparation}

$2 \mathrm{H}-\mathrm{MoS}_{2}$ was used as received. 6-Aminohexanoic acid was neutralized using lithium hydroxide to obtain Li-AHA. 1:1 ratio was kept for $\mathrm{MoS}_{2}$ and LiAHA. ${ }^{39}$ One wt\% of bulk $\mathrm{MoS}_{2}$ was mixed up with Nmethyl-2-pyrrolidone (NMP) and was stirred in a magnetic stirrer for 30 minutes. The required amount of LiAHA in distilled water was stirred in the magnetic stirrer for another 30 mins. The two solutions were mixed and were further sonicated using a probe sonicator for one hour 30 mins followed by centrifugation $(3500 \mathrm{rpm})$ and then drying at $50^{\circ} \mathrm{C}$ for 18 hours. A similar procedure was followed for exfoliation in NMP and mixed solvent except that without the aid of LiAHA. The samples used for analysis were encoded as $2 \mathrm{H}-\mathrm{MoS}_{2}$ (pristine $\left.\mathrm{MoS}_{2}\right), \mathrm{N}-\mathrm{MoS}_{2}\left(\mathrm{MoS}_{2}\right.$ in NMP), NH-MoS $2\left(\mathrm{MoS}_{2}\right.$ in NMP and water) and Li-MoS 2 (LiAHA assisted $\mathrm{MoS}_{2}$ in NMP and water).

\section{RESULTS AND DISCUSSION}

The prepared samples were kept in a vial and the dispersion states were observed. The modified $\mathrm{MoS}_{2}$ samples showed better dispersion states. The $\mathrm{Li}-\mathrm{MoS}_{2}$ solution exhibited a colour change from dark grey to light orange. This colour change can be attributed to better exfoliation that happened to the sample. The change in colour to orange shades could be due to the transfer of charge between acid molecules (AHA) to the exfoliated $\mathrm{MoS}_{2}$ nanosheets. The digital photographs of the samples taken are represented in Fig.-1. 
RASĀYAN J. Chem.

Vol. 12 | No. 4 |1872 - 1880| October - December | 2019

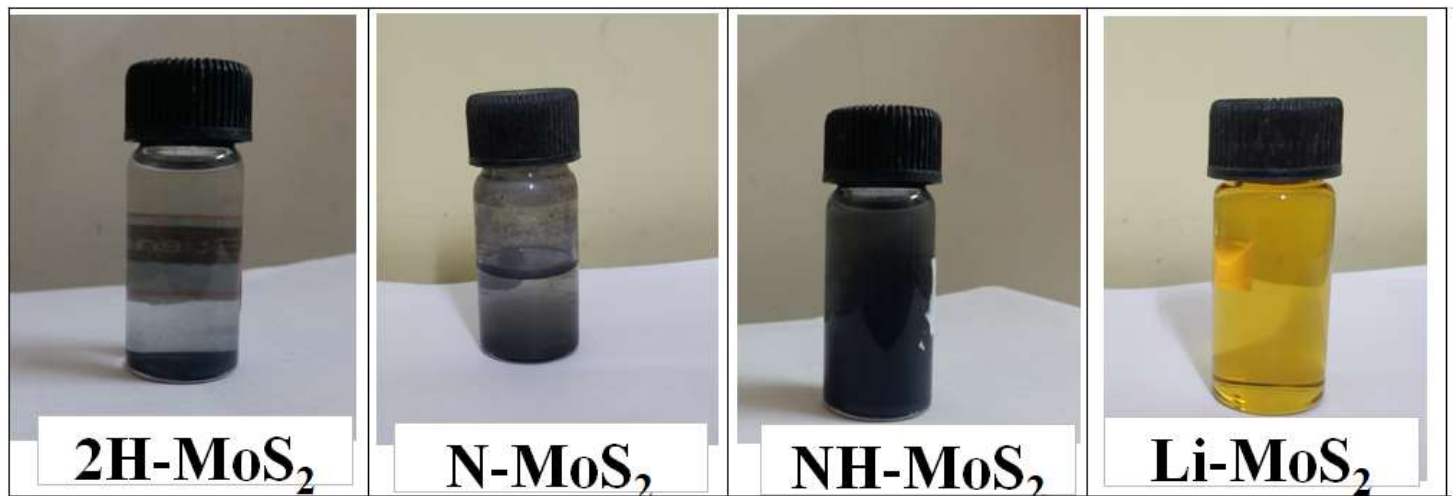

Fig.-1: The Digital Photographs of Prepared $\mathrm{MoS}_{2}$ Samples

\section{X-ray Diffraction Analysis}

The X-ray diffraction (XRD) patterns of the prepared samples are presented in the Fig.-2. It is clear that there are peak shifts in the spectrum for treated samples when compared with the pristine $2 \mathrm{H}-\mathrm{MoS}_{2}$. The diffraction peaks located at $2 \theta=14^{\circ}, 33^{\circ}, 40^{\circ}, 50^{\circ}$ and $59^{\circ}$ correspond to the planes of (002), (100), (103), (105) and (110), respectively, agreeing well with the hexagonal $\mathrm{MoS}_{2}$ (JCPDS card no. 37-1492). The calculated structural parameters, from the XRD measurements are given in Table-1.

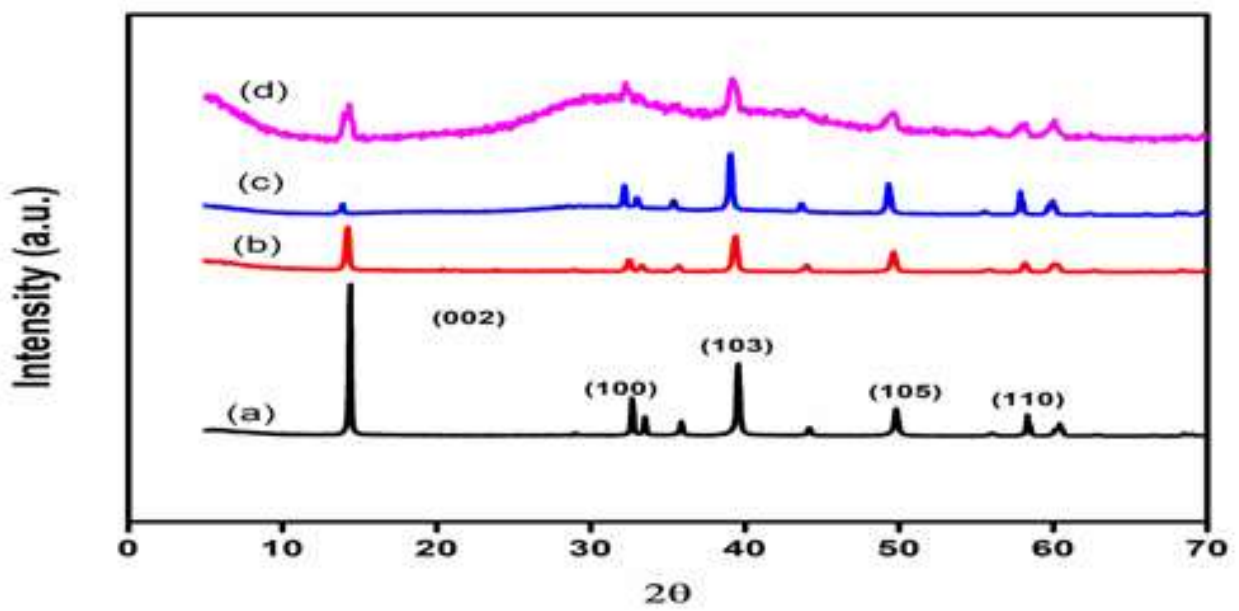

Fig.-2: XRD Spectra of (a). 2H-MoS (b). N-MoS 2 (c).NH-MoS 2 (d) Li-MoS

Table-1: Structural Parameters of Samples Calculated from XRD Spectra

\begin{tabular}{c|c|c|c}
\hline Sample & Average Crystallite Size & Dislocation Density & Lattice Strain \\
\hline $2 \mathrm{H}-\mathrm{MoS}_{2}$ & $15.45(\mu \mathrm{m})$ & $4.189 \times 10^{-3}$ & 0.00187 \\
\hline $\mathrm{N}-\mathrm{MoS}_{2}$ & $9.97(\mathrm{~nm})$ & 0.010 & 0.0294 \\
\hline $\mathrm{NH}-\mathrm{MoS}_{2}$ & $9.69(\mathrm{~nm})$ & 0.0106 & 0.0307 \\
\hline $\mathrm{Li}-\mathrm{MoS}_{2}$ & $8.14(\mathrm{~nm})$ & 0.0150 & 0.0362 \\
\hline
\end{tabular}

It is clear from the table that the average crystallite size is lowest for $\mathrm{Li}-\mathrm{MoS}_{2}$. This reduction in crystallite size is a characteristic of exfoliated $\mathrm{MoS}_{2}{ }^{30-34}$ The decrease in crystallite size is in agreement with the fact that the layers are restacked to the turbostratic structure. ${ }^{35}$ The broadness of the Braggs peaks in Fig.-2, for Li-MoS 2 was due to this reduction of crystallite size. ${ }^{36}$ Similar results were observed by ${ }^{61}$ for graphite.

At reflection $2 \theta=14.5^{0}$, corresponding to (002) peak of $2 \mathrm{H}-\mathrm{MoS}_{2}$, the d spacing is calculated to be 6.15 $\mathrm{A}^{0}$ and it matches with the reported value of $2 \mathrm{H}-\mathrm{MoS}_{2}{ }^{37}$ The increase in d-spacing from $6.15 \mathrm{~A}^{0}$ for $2 \mathrm{H}-$ 
RASĀYAN J. Chem.

Vol. 12 | No. 4 |1872 - 1880| October - December | 2019

$\mathrm{MoS}_{2}$ to $6.318 \mathrm{~A}^{0}$ for $\mathrm{Li}-\mathrm{MoS}_{2}$, which matches with theoretical interlayer spacing of $\mathrm{LiMoS}_{2}{ }^{60}$, indicates that the guest materials have been intercalated into the interlayer space of $\mathrm{MoS}_{2}{ }^{38}$

It is noticed that the intensity of (002) diffraction peak of the $\mathrm{Li}_{-} \mathrm{MoS}_{2}$ decreases as compared to the $2 \mathrm{H}$ $\mathrm{MoS}_{2}$ and it indicates the de-stacking of $\mathrm{MoS}_{2}$ layers. ${ }^{39}$ The decrease in (002) peak intensity suggests the reduction in thickness of bulk $\mathrm{MoS}_{2}$ flakes. ${ }^{40}$

Also in the Fig.-2d, for Li-MoS , a shift in the (002) peaks to lower angles is seen; and it indicates the lattice expansion along the c-axis for the introduction of crystal defects or strains owing to the curvature of the layers ${ }^{[39]}$. This can be understood from the table.1; the lattice strain, as well as the dislocation density, is found to increase in the case of $\mathrm{Li}-\mathrm{MoS}_{2}$. Here the shift is marginal and hence it signifies the minimal lattice distortion which is also in accordance with the structural parameters calculated from the XRD spectrum. These results reflect that when sonicated, $2 \mathrm{H}-\mathrm{MoS}_{2}$ can overcome the van der Waal's forces that hold each layer and the layers get separated.

\section{Fourier Transform Infrared Analysis}

Fig.-3 shows the spectra of the samples. The FTIR peaks for $2 \mathrm{H}-\mathrm{MoS}_{2}$ is very narrow and very broad for monolayer or bilayer $\mathrm{MoS}_{2}{ }^{41}$. Thus the broad peak is shown for the $\mathrm{Li}-\mathrm{MoS}_{2}$ at about $2100 \mathrm{~cm}^{-1}$ can be referred to as an indication that some amount of exfoliation had happened. This broadened peaks, as well as the state of vibration, indicates the exfoliation of the sample and from the peak changes, it is clear that better exfoliation is shown for $\mathrm{Li}-\mathrm{MoS}_{2}$. Compared to $2 \mathrm{H}-\mathrm{MoS}_{2}, \mathrm{Li}-\mathrm{MoS}_{2}$ showed additional peaks at $2920 \mathrm{~cm}^{-1}$ and $2847 \mathrm{~cm}^{-1}$, which can be ascribed to $\mathrm{CH}_{2}$ antisymmetric and symmetric stretching vibrations respectively. ${ }^{42,57-58,4}$ The peak at $1472 \mathrm{~cm}^{-1}$ shows the presence of ammonium salt in the sample These peaks shown for the $\mathrm{Li}_{-} \mathrm{MoS}_{2}$ indicates the presence of amino hexanoic acid, which has been adsorbed to the surface of $\mathrm{MoS}_{2}$, and better modification due to (AHA) which can be observed from the increased peak intensity. The well resolved broad $\mathrm{Mo}=\mathrm{S}$ and Mo-S-Mo peaks for Li-MoS 2 at $720 \mathrm{~cm}^{-1}$ and $910 \mathrm{~cm}^{-1}$ attributes to doubly bridged $\mathrm{S}^{2-}$ and $v(\mathrm{Mo}=\mathrm{S})$ terminal $\mathrm{S}$ stretches respectively. ${ }^{43}$ The peak at $1472 \mathrm{~cm}^{-1}$ shows the presence of $\mathrm{C}-\mathrm{H}$ bending mode in the sample. ${ }^{59}$ The crystalline $2 \mathrm{H}-\mathrm{MoS}_{2}$ peak generally occurs at $365 \mathrm{~cm}^{-1}$, but it was exhibited at $\sim 430 \mathrm{~cm}^{-1}$; this may be due to Mo-S-Mo peaks of highly crystalline $\mathrm{MoS}_{2}{ }^{43}$

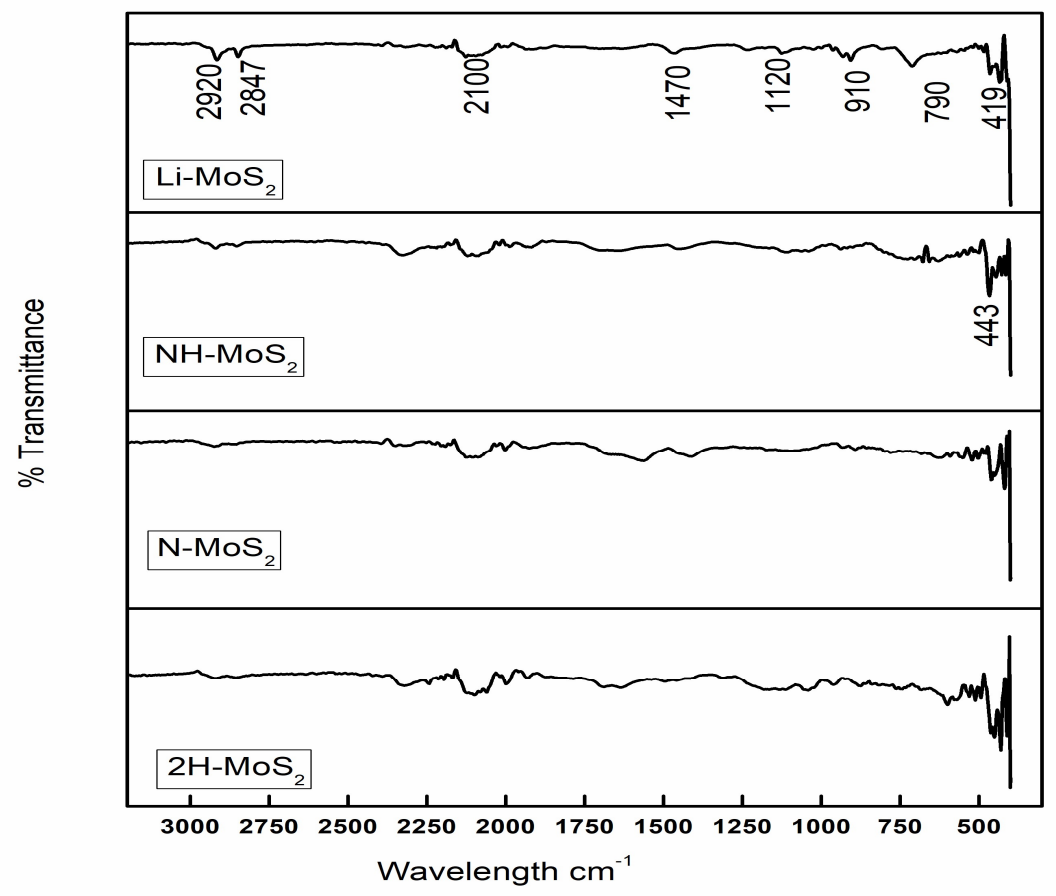

Fig.-3: FTIR Spectra of (a) $2 \mathrm{H}-\mathrm{MoS}_{2}$, (b) N-MoS 2 , (c)NH-MoS 2 , (d) $\mathrm{Li}^{-\mathrm{MoS}_{2}}$

The weak peaks at about $460 \mathrm{~cm}^{-1}$ are assigned to Mo-S vibration ${ }^{[4]}$, and that it is inferred with the results that better exfoliation was seen in $\mathrm{Li}-\mathrm{MoS}_{2}$. 
RASĀYAN J. Chem.

Vol. 12 | No. 4 |1872 - 1880| October - December | 2019

Photoluminescence Spectrum of $\mathrm{MoS}_{2}$

Photoluminescence (PL) is one of the major property that is being exhibited by $\mathrm{MoS}_{2}$ when exfoliated ${ }^{[19]}$. Strong photoluminescence occurs due to an indirect to direct bandgap transition in the d-electron system of $\mathrm{MoS}_{2}{ }^{46}$ The PL spectrum of $2 \mathrm{H}-\mathrm{MoS}_{2}$ and that of $\mathrm{Li}-\mathrm{MoS}_{2}$, shown in Fig.-4 (a) and (b) indicates a strong peak intensity for $\mathrm{Li}-\mathrm{MoS}_{2}$, when compared with that of bulk material; which indicates an indirect bandgap in the bulk material. ${ }^{17}$ The peak at $468 \mathrm{~cm}^{-1}$ in the $2 \mathrm{H}-\mathrm{MoS}_{2}$ is the characteristic peak of bulk $\mathrm{MoS}_{2}$ indicating the presence of indirect bandgap. In Li assisted sample, a broad luminescence from $550 \mathrm{~cm}^{-1}$ to $650 \mathrm{~cm}^{-1}$ is seen. The broad pronounced emission centered at $600 \mathrm{~cm}^{-1}$ corresponds to the B1 direct excitonic transitions at $\mathrm{K}$ point of the Brillouin zone. ${ }^{29,46}$ The peak transition from $650 \mathrm{~cm}^{-1}$ to $720 \mathrm{~cm}^{-1}$ is related to the spin-orbit splitting in the valence band maximum. The emergence of this strong photoluminescence in the Li- $\mathrm{MoS}_{2}$ indicates that luminescence quantum efficiency is much higher in multilayer $\mathrm{MoS}_{2}$ than in bulk ${ }^{6}$, thereby confirming the better exfoliation of the sample. This photoluminescence property of $\mathrm{MoS}_{2}$ when exfoliated can be made use in many applications such as ptype and n-type transistors ${ }^{47}$, inkjet printing ${ }^{48}$, as two-dimensional bandgap semiconductors. ${ }^{6}$

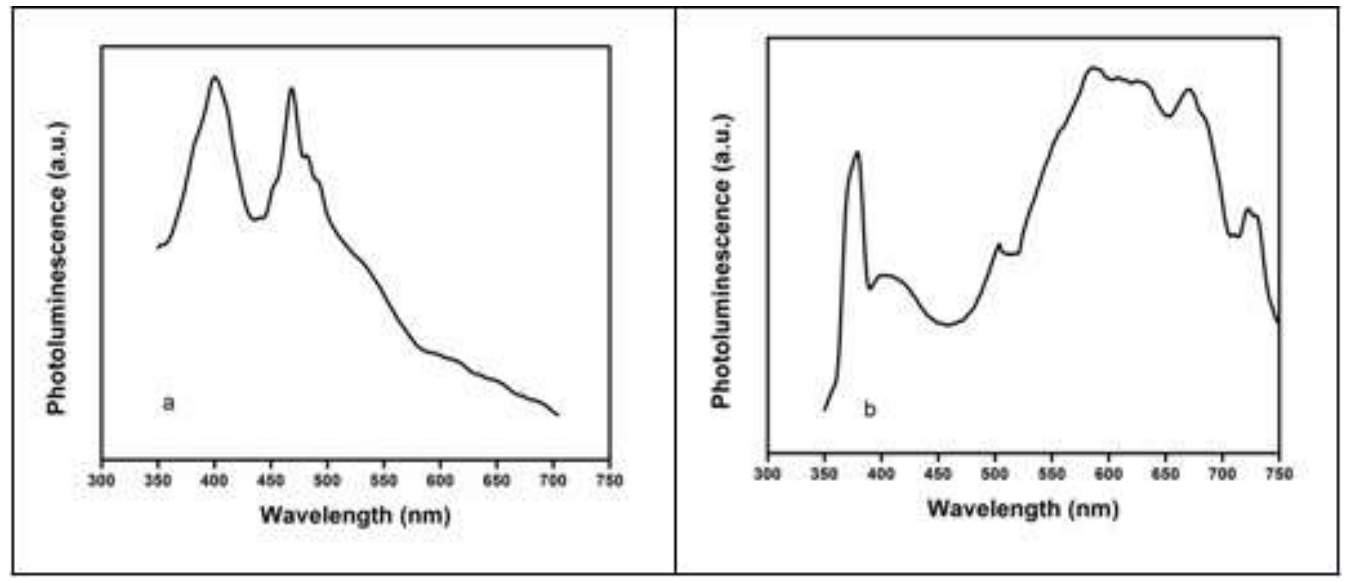

\section{SEM Analysis}

Fig.-4: Photoluminescence Spectrum of (a) $2 \mathrm{H}-\mathrm{MoS}_{2}$ (b) Li-MoS 2

The morphology of the $2 \mathrm{H}-\mathrm{MoS}_{2}$ and treated samples were studied using SEM analysis. The SEM images of the samples are shown in Fig.-5. The SEM images taken at 10,000x and 50,000x magnifications of the $2 \mathrm{H}-\mathrm{MoS}_{2}$ and treated $\mathrm{MoS}_{2}$ samples are studied. The surface details of the samples can be estimated from these images. The multi-layers of pristine $\mathrm{MoS}_{2}$ is clearly observed in the Fig.-5 (a) and (e). The SEM micrographs of treated $\mathrm{MoS}_{2}$ show nanosheet structure with $\mathrm{Li}-\mathrm{MoS}_{2}$ exhibiting much thinner and welldispersed layers. This is attributed to the effect of Li-AHA that effectively resulted in better exfoliation to the $\mathrm{MoS}_{2}$ structure. From the des-stacked layer as seen in Fig.-5 (d) and (h), it is inferred that Li-AHA has a prominent functionalization effect on $\mathrm{MoS}_{2}$ surfaces which can improve further interaction with guest materials.

\section{Antimicrobial Studies}

To realize the extent to which $\mathrm{MoS}_{2}$ could be used in any biological applications, the antimicrobial study was conducted on $\mathrm{Li}-\mathrm{MoS}_{2}$ and $2 \mathrm{H}-\mathrm{MoS}_{2}$ for a comparison. The samples were studied in different organisms like Bacillus cereus, Staphylococcus aureus, Escherichia coli, and Pseudomonas aeruginosa. The figures are as, Fig.-6. Here zone of inhibition test is used to study antimicrobial activity.

From the results, it is very clear that zone of inhibition is more for $\mathrm{Li}-\mathrm{MoS}_{2}$ than that of $2 \mathrm{H}-\mathrm{MoS}_{2}$. Inhibition zone for Pseudomonas aeruginosa is found to be the greatest and for the staphylococcus aureus the smallest. Pseudomonas aeruginosais a gram-negative bacteria and a multidrug-resistant pathogen commonly known for its omnipresence, antibiotic resistance mechanisms. It is always associated with hospital-acquired infections such as ventilator-associated pneumonia and various sepsis syndromes. Treatment of $P$. aeruginosa infections can be difficult due to its natural resistance to antibiotics. Bacillus 
RASĀYAN J. Chem.

Vol. 12 | No. 4 |1872 - 1880| October - December | 2019

cereus is a Gram-positive bacteria that can cause foodborne illness. These kinds of bacterias may grow when food is not properly cooked or kept in unhygienic atmosphere. Similar results were observed by. ${ }^{63}$ From the zone inhibition test results, it is found that $\mathrm{Li}$ assisted $\mathrm{MoS}_{2}$ has shown better zone of inhibition for these kinds of bacteria's, and could be used in biological applications.

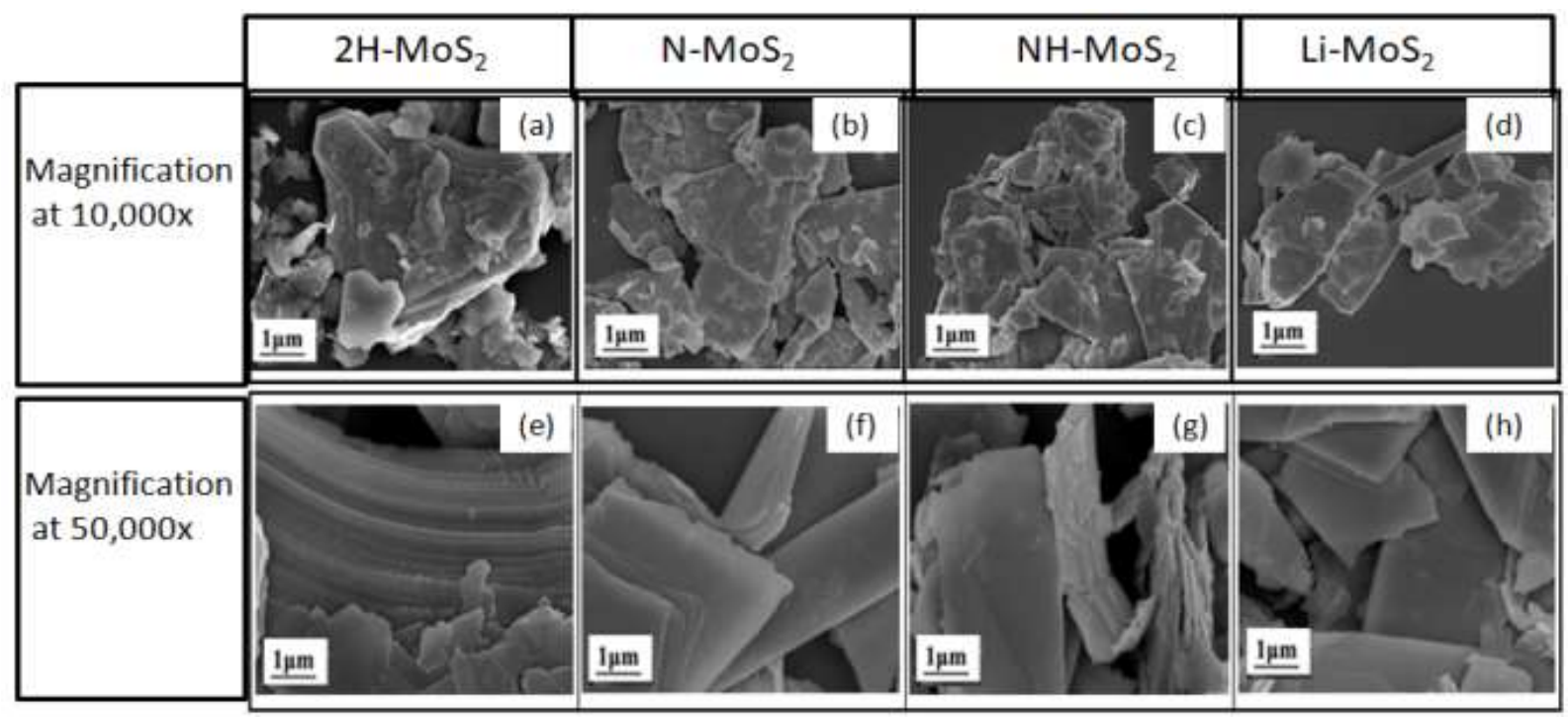

Fig.-5: SEM Images of 2H-MoS 2 and Treated Samples

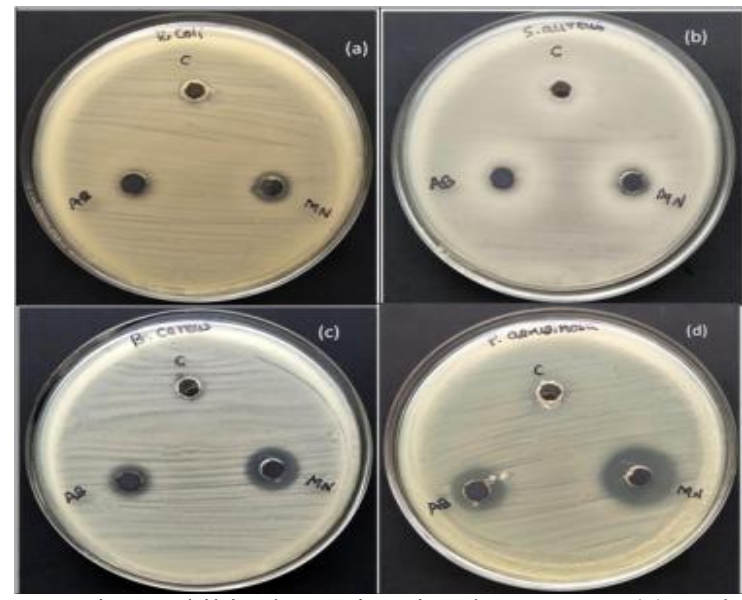

Fig.-6: Images Of Inhibition Zone Being Exhibited By Li assisted $\mathrm{MoS}_{2}$ on : (a)Escherichia coli, (b) Staphylococcus aureus,(c)Bacillus cereus,(d) Pseudomonas aeruginosa.

Table-2: Zone of Inhibition being Exhibited by $2 \mathrm{H}-\mathrm{MoS}_{2}$ and $\mathrm{Li}-\mathrm{MoS}_{2}$

\begin{tabular}{c|c|c}
\hline \multirow{2}{*}{ Name of Organisms } & \multicolumn{2}{|c}{ Zone of Inhibition (mm) } \\
\cline { 2 - 3 } & $\begin{array}{c}\text { Pristine } \\
\mathrm{MoS}_{2}(\mathrm{AB})\end{array}$ & $\begin{array}{c}\mathrm{Li} \text { assisted } \\
\mathrm{MoS}_{2}(\mathrm{MN})\end{array}$ \\
\hline Bacillus cereus & 8 & 13 \\
\hline Staphylococcus aureus & - & 8 \\
\hline Escherichia coli & - & 9 \\
\hline Pseudomonas aeruginosa & 13 & 18 \\
\hline
\end{tabular}

CONCLUSION

The novel approach of treating $\mathrm{MoS}_{2}$ with Li-AHA in a mixed solvent of NMP and deionized water showed better exfoliation results than that without the aid of modifier. The ultrasonication imposes mechanical agitations to the $\mathrm{MoS}_{2}$ dispersion that has the potential to extract layers from the bulk form. In 
RASĀYAN J. Chem.

Vol. 12 | No. 4 |1872 - 1880| October - December | 2019

the presence of $\mathrm{Li}-\mathrm{AHA}$, the $\mathrm{Li}^{+}$ions intercalate to the van der Waal spaces between the layers aiding further separation by increasing the interlayer spacing. Simultaneously, AHA ${ }^{-}$ions get adsorbed to the $\mathrm{MoS}_{2}$ surface imposing a partial negative charge to the surface. The repulsion between the individual sheets prevents the restacking of the sheets. Thus with the help of the modifier single and few-layered $\mathrm{MoS}_{2}$ nanosheets can be synthesized. Further the solvent used, NMP, in the presence of $\mathrm{O}_{2}$ and $\mathrm{H}_{2} \mathrm{O}$, auto oxides into hydroperoxides, which in turn oxidizes $\mathrm{MoS}_{2}$ and facilitates exfoliation. Thus exfoliated $\mathrm{MoS}_{2}$ nanosheets exhibited photoluminescence and antimicrobial activities. The photoluminescence emerges from the indirect to direct bandgap transition, when layers isolated from the bulk structure. Thus exfoliated $\mathrm{MoS}_{2}$ can act as reinforcing filler materials due to the active sites imparted by AHA. This photoluminescence property can be made use in optoelectronic applications. The zone of inhibition test shows that the $\mathrm{Li}-\mathrm{MoS}_{2}$ exhibits zone of inhibition. The bacterial cells first come in contact with exfoliated $\mathrm{MoS}_{2}$ owing to its high surface area. Once contacted, the sharp edges of $\mathrm{MoS}_{2}$ causes membrane stress like cutters that would further disrupt and damages the cell membrane eventually resulting in cell death. Thus the antimicrobial activity coupled along with prepared Li-MoS $\mathrm{Mamples}_{2}$ as a reinforcing ${ }^{62}$ additive to the suitable polymers is promising candidates for biomedical packaging.

\section{REFERENCES}

1. Intek Song, Chibeom Park, Hee Cheul Choi, RSC Adv., 5, 7495(2015), DOI:10.1039/c4ra11852a.

2. K. S. Novoselov, A. K. Geim, S. V. Morozov, D. Jiang, Y. Zhang, S. V. Dubonos, I. V. Grigorieva, A. A. Firsov, Science, 306, 666(2004), DOI: 10.1126/science.1102896

3. K. S. Novoselov, D. Jiang, F. Schedin, T. J. Booth, V. V. Khotkevich, S. V. Morozov, A. K. Geim, Proc. Natl. Acad. Sci., 102, 10451(2005), DOI:10.1073/pnas.0502848102

4. N. Coleman, M. Lotya, A. O'Neill, S. D. Bergin, P. J. King, U. Khan, K. Young, A. Gaucher, S. De, R. J. Smith, I. V. Shvets, S. K. Arora, G. Stanton, H. Y. Kim, K. Lee, G. T. Kim, G. S. Duesberg, T. Hallam, J. J. Boland, J. J. Wang, J. F. Donegan, J. C. Grunlan, G. Moriarty, A. Shmeliov, R. J. Nicholls, J. M. Perkins, E. M. Grieveson, K. Theuwissen, D. W. McComb, P. D. Nellist and V. Nicolosi, Science, 331, 568(2011), DOI:10.1126/science.1194975

5. Rabin Bissessur, K.Y. Peter Liu, Solid State Ionics, 177, 191(2006), DOI:10.1016/S025484(03)00310-9.

6. Andrea Splendiani, Liang Sun, Yuanbo Zhang, Tianshu Li, Jonghwan Kim, Chi-Yung Chim, Giulia Galli, and Feng Wang, Nano Lett., 10, 1271(2010), DOI:10.1021/n1903868w

7. T.F. Jaramillo, K.P. Jorgensen, J. Bonde, J.H. Nielsen, S. Horch, I. Chorkendorff, Science, 317, 100 (2007).

8. J. Kibsgaard, Z.B. Chen, B.N. Reinecke, T.F. Jaramillo, Nat. Mater., 11,963(2012), DOI:10.1038/nmat3439

9. A. Travert, H. Nakamura, A.R. Santen, S. Cristol, J.F. Paul, E.J. Payen, Am. Chem. Soc., 124, 7084 (2002).

10. D. Voiry, M. Salehi, R. Silva, T. Fujita, M.W. Chen, V. Shenoy, G. Eda, M. Chhowalla, Nano Lett., 13, 6222(2013).

11. D. Lembke, S. Bertolazzi, A. Kis, Acc. Chem. Res., 48, 10(2015), DOI:10.1021/ar500274q

12. D. Jariwala, V.K. Sangwan, L.J. Lauhon, T. J. Marks, M.C. Hersam, ACS Nano, 8, 1102 (2014), DOI: $10.1021 / \mathrm{nn} 500064 \mathrm{~s}$

13. S. Mukherjee, R. Maiti, A. Midya, S. Das, S. K. Ray, ACS Photonics, 2, 760(2015), DOI: 10.1021/acsphotonics.5b00111

14. Z. Y. Yin, H. Li, L. Jiang, Y. M. Shi, Y. H. Sun, G. Lu, Q. Zhang, X. D. Chen, H. Zhang, ACS Nano, 6, 74 (2012), DOI:10.1021/nn2024557

15. C. F. Zhu, Z. Y. Zeng, H. Li, F. Li, C. H. Fan, H. J. Zhang, Am. Chem. Soc., 135, 5998 (2013), DOI: $10.1021 /$ ja4019572

16. M. S. Choi, G. H. Lee, Y. J. Yu, D. Y. Lee, S. H. Lee, P. Kim, J. Hone, W. J. Yoo, Nat. Commun., 4, 1624(2013), DOI:/10.1038/ncomms2652

17. K. Golasa, M. Grzeszczyk, K. P. Korona, R. Bozek, J. Binder, J. Szczytko, A. Wysmolek, A. Babinski, Acta Physica Polonica A, 124, 849(2013), DOI:10.12693/APhysPolA.124.849 
RASĀYAN J. Chem.

Vol. 12 | No. 4 |1872 - 1880| October - December | 2019

18. B. Radisavljevic, A. Radenovic, J. Brivio, V. Giacometti, Nat. Nanotechnology, 6, 147 (2011), DOI: $10.1038 /$ nnano.2010.279

19. A. Splendiani, L. Sun, Y. Zhang, T. Li, J. Kim, C. Y. Chim, G. Galli, F. Wang, Nano Lett., 10, 1271 (2010), DOI:10.1021/n1903868w

20. Ramakrishna Matte, A. Gomathi, A. K. Manna, D. J. Late, R. Datta, S. K. Pati, C. N. R. Rao, Angew. Chem., Int. Ed., 49, 4059 (2010), DOI:10.1002/anie.201000009

21. G. Eda, H. Yamaguchi, D. Voiry, T. Fujita, M. Chen, M. Chhowalla, Nano Lett., 11, 5111 (2011), DOI: $10.1021 / \mathrm{nl} 201874 \mathrm{w}$

22. K. G. Zhou, N. N. Mao, H. X. Wang, Y. Peng, H. L. Zhang, Angew. Chem., Int. Ed., 50, 10839 (2011), DOI:10.1002/anie.201105364

23. N. Coleman, M. Lotya, Science, 331, 568 (2011), DOI:10.1126/science.1194975

24. S. Helveg, J. V. Lauritsen, E. Lægsgaard, I. Stensgaard, J. K. Nørskov, B. S. Clausen, H. Topsøe, F. Besenbacher, Phys. Rev. Lett., 84, 951 (2000), DOI:10.1103/PhysRevLett.84.951

25. J. V. Lauritsen, J. Kibsgaard, S. Helveg, H. Topsoe, B. S. Clausen, E. Lagsgaard, F. Besenbacher, Nat. Nanotechnol., 2, 53 (2007), DOI:10.1038/nnano.2006.171

26. Y. Peng, Z. Meng, C. Zhong, J. Lu, W. Yu, Y. Jia, Y. Qian, Chem. Lett., 8, 772 (2001), DOI: $10.1246 / \mathrm{cl} .2001 .772$

27. Q. Li, J. T. Newberg, J. C. Walter, C. Hemminger, R. M. Penner, Nano Lett., 4, 277 (2004), DOI: $10.1021 / \mathrm{nl} 035011 \mathrm{f}$

28. J. Seo, Y. Jun, S. Park, H. Nah, T. Moon, B. Park, J. G. Kim, Y. J. Kim, T. Cheon, J., Angew. Chem., Int. Ed., 46, 8828 (2007), DOI:10.1002/anie.200703175

29. Lili Tao, Hui Long, Bo Zhou, Siu Fung Yu, Shu Ping Lau, Yang Chai, Kin Hung Fung, Yuen Hong Tsang, Jianquan Yao, Degang Xu, Nanoscale, 6, 9713(2014), DOI:10.1039/C4NR02664K

30. K. E. Dungey, M. D. Curtis, J. E. Penner Hanh, Chem. of Mat., 10, 2152(1998), DOI: $10.1021 / \mathrm{cm} 980034 \mathrm{u}$

31. R. F. Frindt, A. S. Arrott, A. E. Curzon, B. Heinrich, S. R. Morrison, T. L. Templeton, R. Divigalpitiya, M. A. Gee, P. Joenson, P. J. Schurer, J. L. Lacombe, J. of Apllied Phy., 70, 6224(1991).

32. X. Zhou, D. Yang, R. F. Frindt, J. of Phy. and Chem. of Sol., 57, 1137(1996).

33. L. Kosidowski, A.V. Powell, Chem. Comm., 2201(1998)

34. G. Cetnarowski, G.W. Leach, Lamgmuir, 22, 8995(2006).

35. C. G. Wu, M. G. Kanatzidis, Mater. Res. Soc. Symp. Proc., 210, 429(1991).

36. Bi-Zhou Lin, Xiao-Ke Pei, Jin-Fei Zhang, Guo-Hua Han, Zhen Li, Pei-De Liu, Ji-Huai Wu, J.M ater . Chem., 14, 2001(2004).

37. M. Ahmad, M. A. Rafiq, Z. Imran, K. Rasool, R. N. Shahid, Y. Javed and M. M. Hasan, J. Appl. Phys., 114, 2011 (2013), DOI:10.1063/1.4816570

38. D’Anne Emmett Spence, “Intercalated $\mathrm{MoS}_{2}$ Nanoparticles For Enhanced Dispersion In Smokes And Obscurants", Faculty of the Graduate School of the University of Maryland, College Park in partial fulfillment of the requirements for the Degree of Master of Science (2003).

39. B. Bindhu, B. K. Sharu, M. S. Gopika, P. K. Praseetha, K. Veluraja, RSC Adv., 6, 22026(2016), DOI: 10.1039/C5RA25368C.

40. V. H. Pham, K. H. Kim, D. W. Jung, K. Singh, E. S. Oh, J. S. Chung, J. Power Sources, 244, 280 (2013), DOI:10.1016/j.jpowsour.2013.01.053

41. R. R. Chianelli, M. B. Dines, Inorg. Chem., 17, 2758(1978), DOI:10.1021/ic50188a014

42. Keqing Zhou, Jiajia Liu, Wenru Zeng, Yuan Hu, Zhou Gui, Comp. Sci. and Tech., 107, 120 (2015), DOI:10.1016/j.compscitech.2014.11.017.

43. A. Vadivel Murugan, Mathieu Quintin, Marie-Hélène Delville, Guy Campet, Annamraju Kasi Viswanath, J. of Mat. Res., 21, 112 (2006).

44. S. S. Liu, X. B. Zhang, H. Shao, J. Xu, F.Y. Chen, Y. Feng, Mater. Lett., 73, 223 (2012), DOI: 10.1016/j.matlet.2012.01.024

45. J. Zhao, Zhaochun Zhang, Shanshan Yang, Houli Zheng, Yunbo Li, J. of Alloys and Comp., 559, 87 (2013), DOI:10.1016/j.jallcom.2013.01.067 
RASĀYAN J. Chem.

Vol. 12 | No. 4 |1872 - 1880| October - December | 2019

46. Lijuan Ye, Haiyan Xu, Dingke Zhang, Shijian Chen, Mat. Res. Bull., 55, 221 (2014), DOI: 10.1016/j.materresbull.2014.04.025.

47. Zhiming Wang, Springer Science \& Business Media, (2013).

48. Jian Zheng, Han Zhang, Shaohua Dong, Yanpeng Liu, Chang Tai Nai, Hyeon Suk Shin, Hu Young Jeong, Bo Liu and Kian Ping Loh, Nat. Comm., 5, 2995(2014), DOI:10.1038/Ncomms3995

49. Jonathan Coleman, Mustafa Lotya, Arlene O Neill, Shane Bergin, Paul King, Umar Khan, Karen Young, Alexandre Gaucher Sukanta De, Ronan Smith, Igor Shvets, Sunil Arora, George Stanton, Hye-Young Kim, Kangho Lee, Gyu Tae Kim, Georg Duesberg, Toby Hallam, John Boland, Jing Jing Wang, John Donegan, Jaime Grunlan, Gregory Moriarty, Aleksey Shmeliov, Rebecca Nicholls, James Perkins, Eleanor Grieveson, Koenraad Theuwissen, David McComb, Peter Nellist, Valeria Nicolosi, Science, 331, 568(2011), DOI:10.1126/science.1194975

50. Ali Jawaid, Dhriti Nepal, Kyoungweon Park, Michael Jespersen, Anthony Qualley, Peter Mirau, Lawrence Drummy, Richard Vaia, Chem. Mater., ACS, 28, 337 (2016), DOI: 10.1021 /acs.chemmater.5b04224

51. O'Neill, U. Khan, J. N. Coleman, Chem. Mater., 24, 2414(2012), DOI:10.1021/cm301515z

52. A. P. Gaur, S. Sahoo, M. Ahmadi, S. P. Dash, M. J. F. Guinel, R. S. Katiyar, Nano Lett., 14, 4314 (2014), DOI:10.1021/n1501106v.

53. J. Shen, Y. He, J. Wu, C. Gao, K. Keyshar, X. Zhang, Y. Yang, M. Ye, R. Vajtai, J. Lou, P. M. Ajayan, Nano Lett., 15, 5449 (2015), DOI:10.1021/acs.nanolett.5b01842

54. U. Khan, A. O'Neill, M. Lotya, S. De, J. N. Coleman, Small, 6, 864 (2010), DOI: $10.1002 / \mathrm{smll} .200902066$

55. Y. Hernandez, V. Nicolosi, M. Lotya, F. M. Blighe, Z. Sun, S. De, I. T. McGovern, B. Holland, Y. K. Gun'Ko, J. J. Boland, P. Niraj, G. Duesberg, S. Krishnamurthy, R. Goodhue, J. Hutchison, A. C. Ferrari, J. N. Coleman, Nat. Nanotechnol., 3, 563 (2008), DOI:10.1038/nnano.2008.215.

56. V. Forsberg, R. Zhang, J. Bäckström, C. Dahlström, B. Andres, M. Norgren, PLoS ONE, 11(4), e0154522(2016), DOI:10.1371/journal.pone.0154522

57. G. Pircheraghi, H. Nazockdast, M. M. Salehi, Micro Nano Lett, 6, 628 (2011), DOI: $10.1049 / \mathrm{mnl} .2011 .0074$

58. B. Harintharavimal, I. Muthmirah, U. W. Mat, H. Azman, Polym Compos, 32, 1927 (2011), DOI: $10.1002 / \mathrm{pc} .21207$

59. N. Li, X. Zhang, S. Chen, X. Hou, Y. Liu, X. Zhai, Mater. Sci. Eng., B, 176, 688 (2011), DOI: $10.1016 /$ j.mseb.2011.02.016

60. Xiaobin Fan, Pengtao Xu, Dekai Zhou, Yifan Sun, Yuguang Li, Minh An Nguyen, Mauricio Terrones, Thomas Mallouk, Nano Lett., 15, 5956 (2015).

61. V. Sivasankar, E. Senthil Kumar, R. Suresh Babu, S. Raghu, R. A. Kalaivani, Rasayan J. Chem., 10(4), 1232 (2017), DOI:10.31788/RJC.2019.1235045

62. Rajesh Prabha, Edwin Raja Dhas, Rasayan J. Chem., 10(3), 729 (2017), DOI: 10.7324/RJC.2017.1031765

63. Rahayu, Hartono, P. Sugita, Rasayan J. Chem., 11(2), 762 (2018), DOI:10.31788/RJC.2018.1122076

[RJC-5332/2019] 